\title{
LAPAROSCOPIC BURCH SURGERY: IS THERE ANY ADVANTAGE IN RELATION TO OPEN APPROACH?
}

\author{
CARLOS A. BEZERRA, ALEXANDRE O. RODRIGUES, ALEXANDRE L. SEO, JOSÉ M.C. \\ RUANO, MILTON BORRELLI, ERIC R. WROCLAWSKI
}

Sections of Urology and Gynecology, ABC Medical School, Santo André, São Paulo, Brazil

\begin{abstract}
Introduction: Surgery represents the main therapeutic modality for stress urinary incontinence. In incontinent patients with urethral hypermobility, the retropubic colposuspension by Burch technique is one of the surgeries that present better long-term results. Current trends towards performing minimally invasive techniques led proposing the Burch surgery through videolaparoscopy. The laparoscopic technique's long-term efficacy is a highly controversial issue. However, even if late results turn out to be satisfactory, the assumed advantages of laparoscopy (faster recovery, less pain, early return to daily activities, etc.) must be evident, in order to justify the use of this minimally invasive surgical access.

Materials and Methods: We reviewed our records and analyzed the medical charts of 26 female patients who underwent Burch surgery by open approach and 36 female patients by laparoscopic approach, between May 1999 and February 2001. The satisfaction level, surgical complication rates, surgery length, hospital stay and return to daily activities were analyzed.

Results: Mean age was 42 years, ranging from 27 to 68 years. Epidemiological data from both groups were not statistically different. Patients operated by laparoscopic route had a shorter hospital stay $(\mathrm{p}=0.002)$ and a faster return to their daily activities $(\mathrm{p}<0.001)$. However, there were no statistical differences in the following parameters: surgical time $(\mathrm{p}=0.11)$, surgical complications $(\mathrm{p}=0.98)$, patient satisfaction immediately $(\mathrm{p}=0.77)$ and 90 days following surgery $(\mathrm{p}=0.84)$, surgery acceptance $(\mathrm{p}=0.85)$, indication of this surgery to a friend $(\mathrm{p}=0.93)$ and score given to the procedure $(\mathrm{p}=0.68)$.

Conclusions: Even if the efficacy of both methods is similar, we did not observe significant advantages of laparoscopic surgery over open surgery, concerning the recovery in recent post-operative period.
\end{abstract}

Key words: urinary incontinence, stress; urethra; surgery; retropubic; laparoscopic Int Braz J Urol. 2004; 30: 230-6

\section{INTRODUCTION}

Stress urinary incontinence (SUI) in women is an entity that presents high prevalence and significant medical, social and psychological consequences. Surgery represents the most effective therapy and is commonly used for its treatment. It is fundamental to consider the type of SUI when choos- ing the surgical technique. In patients with bladder neck hypermobility, retropubic colposuspension by Burch technique is one of the most used alternatives. Current trends towards performing less invasive surgeries with shorter hospital stay period, lower indexes of complications and faster rehabilitation of patients led to the development of laparoscopic surgery. In 1991, Vancaille \& Schuessler described 
the Burch surgery by laparoscopic approach, performed with a technique similar to conventional surgery (1). Despite the assumed advantages of being a minimally invasive procedure, works analyzing the laparoscopic technique focus on assessment of efficacy and duration of long-term results. The efficacy of the laparoscopic procedure is quite controversial. However, even the results are similar for both techniques, it is still necessary to demonstrate the presumed advantages in patients' recovery. This issue is rarely discussed in the pertinent literature.

We performed an analysis of our casuistry in order to verify whether there is any advantage of videolaparoscopic surgery in relation to open surgery, using as parameters the satisfaction level, index of problems correlated to the surgical procedure, length of surgery and period of hospital stay and rehabilitation of patients.

\section{MATERIALS AND METHODS}

We performed a retrospective comparative study, analyzing 62 patients with SUI, undergoing surgical treatment in the period from May 1999 to February 2001. Burch technique by open approach was employed in 26 patients (42\%) and laparoscopic Burch technique in 36 patients $(58 \%)$.

All patients underwent a detailed clinical examination, as well as complementary tests. The patient profile was designed for each group according to the following criteria: age, previous surgeries for treating SUI, parity, hormonal condition, body mass index (BMI), presence of cystocele, rectocele, perineal rupture and uterine prolapse. Patients were regarded as having genuine SUI due to urethral hypermobility when the urodynamic study showed leak point pressure superior to $90 \mathrm{~cm} \mathrm{H}_{2} \mathrm{O}$. Intraoperative and postoperative data such as surgical time, associated surgeries and hospitalization period were assessed. We also evaluated the complications occurring intraoperatively and on the 7th, 30th and 90th postoperative day. We considered as intercurrences abdominal pain (when the use of analgesics were required), problems with surgical wound (infection, hematoma, dehiscence), fever, urinary tract infection, urinary retention or persistence of urinary loss symptoms (recurrence).
Burch surgery by open approach was performed with the patient in lithotomy position, through Pfannenstiel incision. Retzius space was extraperitoneally dissected, allowing approaching the urethra, bladder neck and Cooper's ligament, aided by the identification of the vaginal culs-de-sac through presentation with vaginal mounted gauze and palpation of the $18 \mathrm{~F}$ vesical catheter balloon. Then 2 or 3 stitches were applied with 2-0 polygalactine suture between the vaginal dome, at the level of bladder neck, and Cooper's ligament. The laparoscopic technique was performed by transperitoneal approach through 3 punctures: $10-\mathrm{mm}$ puncture in the umbilicus (optics) plus another 2 auxiliary punctures in McBurney's point, to the right $(5 \mathrm{~mm})$ and its mirror-image point to the left $(10 \mathrm{~mm})$. All other steps were similar to open surgery $(2,3)$. Two stitches were applied on each side of the bladder neck in all patients.

As a criterion to objectively assess surgical outcome during post-operative follow-up, all patients underwent a rigorous physical examination with direct visualization of urine loss through the urethra following stress maneuvers, with the patient standing and with vesical repletion. An inquiry about the satisfaction level was also conducted, questioning if they would perform again the same procedure and if they would indicate the procedure to other persons. Once the patients answered the questions, we asked them to give a score (from 0 to 10) concerning the treatment employed.

The statistical analysis was made with the Epi info $2000^{\circledR}$ software using the qui-square test $\left(\chi^{2}\right)$ and the Fisher's exact test with $95 \%$ confidence interval $(p<0.05)$ for all the assessed parameters.

\section{RESULTS}

Concerning patient age, we had as average 42 years, ranging from 27 to 68 years. No statistical difference was observed between the 2 groups when we assessed parity (average of 5 vaginal deliveries), hormonal conditions and body mass index, as well as the presence of vaginal dystopias $(95 \%$ of patients presented some degree of cystocele and $75 \%$ some degree of rectocele). Three patients (8\%) undergoing laparoscopic surgery and $2(7 \%)$ undergoing open 
surgery reported previous surgical treatment for SUI (Table-1).

Mean surgical time was 172 minutes, with 186 minutes being the average for laparoscopic surgeries and 153 the length of open ones. One or more associated surgical procedures were performed in 20 patients (77\%) undergoing open surgery and $35(97 \%)$ undergoing laparoscopy (Tables-2 and 3).

There were $4(11 \%)$ intraoperative surgical intercurrences in the laparoscopic group (3 bladder lesions and one colon perforation) and $1(4 \%)$ case in the open group (bladder lesion), $\left(\mathrm{p}=0.93, \chi^{2}=0.33\right)$.

Table 1 - Assessment of parity, hormonal condition, body mass index, vaginal dystopias and previous surgical treatment of patients studied.

\begin{tabular}{|c|c|c|c|c|}
\hline Parameter & Variable & $\begin{array}{l}\text { Laparoscopic Burch } \\
\quad \mathrm{n}=\mathbf{3 6}\end{array}$ & $\begin{array}{c}\text { Open Burch } \\
n=26\end{array}$ & p Value \\
\hline Parity & $\begin{array}{l}\text { Below or equal to } 5 \\
\text { Above } 5\end{array}$ & $\begin{array}{ll}26 & (72.2 \%) \\
10 & (27.8 \%)\end{array}$ & $\begin{array}{r}17(65.4 \%) \\
9(34.6 \%)\end{array}$ & 0.6 \\
\hline Hormonal condition & $\begin{array}{l}\text { Menacme } \\
\text { Menacme + oral } \\
\text { anticonceptive } \\
\text { Climacteric period with } \\
\text { hormonal replacement } \\
\text { Climacteric period without } \\
\text { hormonal replacement }\end{array}$ & $\begin{array}{rr}25 & (69.4 \%) \\
5 & (13.9 \%) \\
5 & (13.9 \%) \\
1 & (2.77 \%)\end{array}$ & $\begin{array}{r}16(51.5 \%) \\
2 \quad(7.7 \%) \\
4(15.4 \%) \\
4(15.4 \%)\end{array}$ & 0.3 \\
\hline Body mass index & $\begin{array}{l}\text { BMI }<25 \\
\text { BMI } 25 \text { to } 30 \\
\text { BMI }>30\end{array}$ & $\begin{array}{c}12(33.3 \%) \\
19(52.8 \%) \\
5(13.88 \%)\end{array}$ & $\begin{array}{r}5(19.2 \%) \\
15(57.7 \%) \\
6(23.1 \%)\end{array}$ & 0.4 \\
\hline Vaginal dystopias & $\begin{array}{l}\text { Cystocele absent } \\
\text { Cystocele present } \\
\text { Rectocele absent } \\
\text { Rectocele present }\end{array}$ & $\begin{array}{rr}2 & (5.5 \%) \\
34 & (94.5 \%) \\
9 & (25 \%) \\
27 & (75 \%)\end{array}$ & $\begin{array}{r}1(3.8 \%) \\
25(96.2 \%) \\
7(26.9 \%) \\
19(73.1 \%)\end{array}$ & $\begin{array}{l}0.7 \\
0.9\end{array}$ \\
\hline Perineal Rupture & $\begin{array}{l}\text { Absent } \\
\text { Incomplete } \\
\text { Complete }\end{array}$ & $\begin{array}{rr}9 & (25 \%) \\
7 & (19.4 \%) \\
20 & (55.6 \%)\end{array}$ & $\begin{array}{r}5(19.2 \%) \\
2 \quad(7.7 \%) \\
19(73.1 \%)\end{array}$ & 0.3 \\
\hline Previous surgeries & $\begin{array}{l}\text { Occurred } \\
\text { Did not occur }\end{array}$ & $\begin{array}{rr}3 & (8.3 \%) \\
33 & (91.7 \%)\end{array}$ & $\begin{array}{c}2(7.7 \%) \\
24(92.3 \%)\end{array}$ & 0.9 \\
\hline
\end{tabular}

Table 2 - Number of surgical procedures associated with Burch surgery.

\begin{tabular}{lccc}
\hline & 1 Procedure & 2 Procedures & 3 Procedures \\
\hline Open Burch Surgery & 14 & 5 & 1 \\
Laparoscopic Burch Surgery & 19 & 15 & 1 \\
\hline
\end{tabular}


Table 3 - Types of surgical procedures associated with Burch surgery.

\begin{tabular}{ccccc}
$\begin{array}{c}\text { Posterior } \\
\text { Colpoperineoplasty }\end{array}$ & Tubal Ligation & Hysterectomy & Annexectomy Others \\
\hline 19 & 5 & 2 & 2 & 2 \\
30 & 10 & 4 & 1 & 2 \\
\hline
\end{tabular}

In relation to the hospitalization period, we observed an average of 3 days, lower in the group undergoing laparoscopic surgery (statistically significant), Table-4.

When analyzing the postoperative results, 59 patients $(95.16 \%)$ reported being dry or having minimal urinary loss, with no statistically significant difference between the 2 groups (Table-5).

Tables-6, 7 and 8 show the complications at 7th, 30th and 90th postoperative days.

Table 4-Hospitalization time of patients undergoing Burch surgery (mean 3 days) $\left(\chi^{2}=13.25, p=0.002\right)$.

\begin{tabular}{lcc}
\hline & $\leq \mathbf{3}$ days & $>\mathbf{3}$ days \\
\hline Open Burch Surgery & 11 & 13 \\
Laparoscopic Burch Surgery & 31 & 5 \\
\hline
\end{tabular}

Table 5-Assessment of patients on the 90th postoperative day $\left(\chi^{2}=0.70, p=0.77\right)$.

Dry / Better Equal / Worse

\begin{tabular}{lll} 
Open Burch Surgery & 24 & 2 \\
Laparoscopic Burch Surgery & 35 & 1 \\
\hline
\end{tabular}

Table 6 - Presence of complications until the 7th postoperative day $\left(\chi^{2}=17.48, p<0.001\right)$.

\begin{tabular}{lcc}
\hline & $\begin{array}{c}\text { With } \\
\text { Complications }\end{array}$ & $\begin{array}{c}\text { Without } \\
\text { Complications }\end{array}$ \\
\hline Open Burch Surgery & 17 & 7 \\
Laparoscopic Burch Surgery & 5 & 31 \\
\hline
\end{tabular}

When questioned on the 90th postoperative day about satisfaction with surgical treatment, 30 patients (83\%) from laparoscopic group and 23 (86\%) undergoing open surgery were satisfied, with no difference between groups $\left(p=0.84, \chi^{2}=0.319\right)$. Thirtythree $(91.66 \%)$ patients from laparoscopic group and $25(96.15 \%)$ patients from open surgery group would accept to undergo a hypothetical reintervention $(\mathrm{p}=$ $\left.0.85, \chi^{2}=0.503\right)$. Thirty $(83 \%)$ patients from laparoscopic group and 21 (81\%) from open group would indicate this kind of surgical procedure to a friend presenting the same clinical situation, with no difference between groups ( $\mathrm{p}=0.93, \chi^{2}=0.068$ ).

When asked to give a score from 0 to 10 to their surgeries, $30(83 \%)$ patients from laparoscopic group and $20(77 \%)$ from open surgery group indicated a score between 8 and 10 (Table-9).

Table 7 - Presence of intercurrences until the 30th postoperative day $\left(\chi^{2}=6.36, p=0.01\right)$.

\begin{tabular}{lcc}
\hline & $\begin{array}{c}\text { With } \\
\text { Complications }\end{array}$ & $\begin{array}{c}\text { Without } \\
\text { Complications }\end{array}$ \\
\hline Open Burch Surgery & 11 & 13 \\
Laparoscopic Burch Surgery & 5 & 31 \\
\hline
\end{tabular}

Table 8 - Presence of intercurrences until 90th post-operative day $\left(\chi^{2}=0.96, p=0.32\right)$.

\begin{tabular}{lcc}
\hline & $\begin{array}{c}\text { With } \\
\text { Complications }\end{array}$ & $\begin{array}{c}\text { Without } \\
\text { Complications }\end{array}$ \\
\hline Open Burch Surgery & 7 & 19 \\
Laparoscopic Burch Surgery & 6 & 30 \\
\hline
\end{tabular}


Table 9 - Which score would you give to your surgery? $\left(\chi^{2}=0.74, p=0.68\right)$.

\begin{tabular}{lccc}
\hline & $\mathbf{0 - 4}$ & $\mathbf{5 - 7}$ & $\mathbf{8 - 1 0}$ \\
\hline Open Burch Surgery & 3 & 3 & 20 \\
Laparoscopic Burch Surgery & 4 & 2 & 30 \\
\hline
\end{tabular}

\section{DISCUSSION}

Burch colposuspension surgery (4) has been the procedure of choice for many gynecologists and urologists for treating SUI due to the good long-term results observed. The same surgery, performed by laparoscopic approach, is gaining popularity because it supposedly presents advantages such as, smaller incisions with better esthetic results, easier access to Retzius space, improved visualization of the surgical field, minimal intraoperative blood loss and lower requirement of analgesics in the postoperative period, in addition to lower cost, shorter hospital stay and rehabilitation period of patients (5-7). Many authors describe cure rates for laparoscopic Burch surgery similar to those obtained with open technique, however with comparatively shorter follow-up (8-11).

The literature contains descriptions of several modifications and technical facilities (staplers, bone fixators, synthetic meshes, biological glues) used in an effort to make the performance of laparoscopic Burch surgery easier and faster and, consequently, more accessible to surgeons (8). Many of those surgeries, due to their extensive modifications, should not even be referred to as Burch surgery (3). However, no definitive conclusion has been drawn about such modifications. It is not known if they impair the efficacy that was previously established for the open technique, since global results are quite controversial. For example, McDougall et al., observed success in only $30 \%$ of patients operated by modified technique with staplers (using polyester suture fixed by clip instead of stitches), in a 36-months follow-up (12). There are several other conflicting results in the literature about the efficacy of laparoscopic technique, as well as its comparison with the open technique. Lose reviewed 15 works on laparoscopic Burch sur- gery and found a wide technical variability in the technique employed and cure criteria, with only one work being prospective and randomized (13).

Su et al., when analyzing 92 operated patients ( 46 by laparoscopy and 46 by open surgery), observed that surgical time was similar, however the cure rate was lower with laparoscopic approach, corresponding to $80 \%$ in laparoscopy and $96 \%$ in open surgery. Complication rate was $11 \%$ and $17 \%$, respectively (14). Kohli et al. observed a shorter surgical time with laparoscopic approach (110 minutes versus 66 minutes). Hospital stay was longer with open route (mean 2.1 days versus 1.3 days). There were no intraoperative intercurrences in any group (15).

In a retrospective study, conducted by Miannay et al. (16) comparing both techniques in 72 patients, a shorter surgical time was observed with open approach. However, patients reported a lower pain index with laparoscopic approach, requiring less postoperative analgesia. Hospital stay was also shorter with laparoscopic approach (mean 3 days with laparoscopy versus 6.3 days with open surgery). Cure and improve rates after 1 year, respectively, were $79 \%$ and $85 \%$ for laparoscopy, and $69 \%$ and $82 \%$ for open surgery. After 2 years, cure and improve rates dropped to $68 \%$ and $80 \%$ for laparoscopy, and to $64 \%$ and $75 \%$ for open surgery, showing a decrease in cure index when patients were assessed for a longer period.

Another comparative work was performed by Das using 10 patients operated by laparoscopy and 10 by open approach. They demonstrated a lower requirement for analgesia, shorter length of vesical stenting and shorter hospital stay with laparoscopic approach. However, the healing index after 10 months was $100 \%$ for open surgery and $90 \%$ for laparoscopy. After 36 months, this index dropped to $50 \%$ and $40 \%$. Satisfaction level, however, was superior with laparoscopic surgery, corresponding to $60 \%$ in open surgery and $90 \%$ in laparoscopic surgery (17).

On the other hand, Saidi et al. retrospectively studied 70 patients undergoing laparoscopy and 87 undergoing open surgery, with a mean follow-up of 15 months, and described a shorter surgical time, shorter hospital stay and faster rehabilitation in laparoscopic group. Cure and complication rates (91\% 
in laparoscopic group and $92 \%$ in open surgery group) were similar (18).

Moehrer et al. performed a systematic review of the literature, searching only the best evidences (randomized clinical trials) that analyzed laparoscopic Burch surgery. They suggest that the method can provide faster recovery, but with higher risk of complications. However, evidences are weak and prospective randomized works are required to better clarify this issue (19).

In spite of this discussion, works did not clearly analyze whether laparoscopic surgery actually represents an advance for the patient, upon perceiving that it is a less invasive procedure.

In our study, we observed that $83 \%$ of patients undergoing laparoscopy and $61.5 \%$ undergoing open surgery were free of urinary symptoms 90 days after surgery. When added to symptoms improvement, which for patients indicates surgical success, these values rise to $97 \%$ and $92 \%$, respectively. Obviously, a long-term follow-up is required for these patients, in order to verify the maintenance of such indexes, since several studies demonstrate deterioration in results with time.

However, if we analyze the initial results, aiming to assess morbidity and faster recovery of patients, it is not clear if laparoscopic surgery is more advantageous. Intraoperative complications occurred in $11 \%$ of laparoscopic surgeries and $3 \%$ of open surgeries. Bladder lesion was the most prevalent complication, followed by one case of colon perforation. These figures are compatible with literature (20).

When assessing the presence of complications on 7th, 30th and 90th PO days, we observed that with open approach there is a significant decrease in the complication rate. On the 7th PO day, there was a statistically significant difference in complications between the 2 techniques. Such difference decreases on the 30th PO day, becoming statistically non-significant on the 90th PO day. We can conclude that laparoscopic surgery provided, in addition to shorter hospital stay, better rehabilitation in the first ninety days following the procedure. However, we observed that this shorter hospital stay and better convalescence had no impact on the assessment of satisfaction by the patients concerning their surgeries, generally evaluated as satisfactory. These findings can be associated with the fact that, in surgical procedures on the lower abdomen, with extraperitoneal access, the impact for the patient is already naturally low. Thus, the performance of laparoscopic method may not bring the expected benefits of a minimally invasive procedure. Prospective randomized studies are required to clarify this issue and to determine whether there is any advantage of laparoscopic Burch surgery or not.

\section{CONCLUSION}

Laparoscopic and open approaches for performing Burch surgery have similar short-term cure indexes, as well as similar occurrence of complications and satisfaction level of patients, with hospital stay and rehabilitation period being lower in those who are operated by laparoscopic approach. However, in the patient's point of view, laparoscopic Burch surgery did not present significant advantages in relation to open surgery in the population under study.

\section{REFERENCES}

1. Vancaillie TG, Schuessler W: Laparoscopic bladder neck suspension. J Laparoendos Surg. 1991; 3: 16973.

2. Juliano RV, Barboza CP, Bezerra CA: Laparoscopic Burch surgery. J Bras Urol. 1998; 24: 280-4. [in Portuguese]

3. Juliano RV, Bezerra CA, Machado MT, Wroclawski E, Borrelli M: Treatment of stress urinary by laparoscopic Burch surgery. In: Rubinstein I (ed.), Urinary Incontinence in Women. Ed. Atheneu. 2001; pp. 195-201. [in Portuguese]

4. Burch JC: Urethrovaginal fixation to Cooper's ligament for the correction of stress incontinence, cystocele, and prolapse. Am J Obstet Gynecol. 1961; 88: 281-90.

5. Tamussino KF, Zivkov F, Pieber D, Moser F, Haas J, Ralph G: Five-year results after anti-incontinence operations. Am J Obstet Gynecol. 1999; 181: 1347-52.

6. Ross JV: Laparoscopic Burch repair compared to laparotomy Burch for cure of urinary stress incontinence. Int Urogynecol J. 1995; 6: 323-8.

7. Bezerra CA, Machado MT, Juliano RV, Ruano JMC, 
Barbosa CP, Borreli M, et al.: Laparoscopic Burch surgery in public institution; cost comparative analysis. J Bras Urol. 1999; 25: 68-72. [in Portuguese]

8. Miklos JR, Kohli N: Laparoscopic paravaginal repair plus Burch colposuspension: Review and descriptive technique. Urology. 2000; 56 (Sup 6A): 64-9.

9. Cooper MJ, Carlo G, Lam A, Carolton M: A review of results in a series of 113 laparoscopic colposuspensions. Aust N Z J Obst Gynecol. 1996; 36: 44-9.

10. Papasakelariou C, Papasakelariou B: Laparoscopic bladder neck suspension. J Am Assoc Gynecol Laparosc. 1997; 4: 185-8.

11. Lobel RW, Davis GD: Long-term results of laparoscopic Burch colposuspension. J Am Assoc Gynecol Laparosc. 1998; 91: 55-9.

12. McDougall EM, Heidorn CA, Portis AJ, Klutke CG: Laparoscopic bladder neck suspension fails the test of time. J Urol. 1999; 162: 2078-81.

13. Lose G: Laparoscopic Burch colposuspension. Acta Gynecol Scand Suppl. 1998; 168: 29-33.

14. Su TH, Wang KG, Hsu CY, Wei HJ, Hong BK: Prospective comparison of laparoscopic and traditional colposuspensions in the treatment of genuine stress incontinence. Acta Obstet Gynecol Scand. 1997; 76: 576-82.
15. Kohili N, Jacobs PA, Sze EH, Roat TW, Karram MM: Open compared with laparoscopic approach to Burch colposuspension: a cost analysis. Obstet Gynecol. 1997; 90: 411-5.

16. Miannay E, Cosson M, Lanvin D, Querleu D, Crepin $\mathrm{G}$ : Comparison of open retropubic and laparoscopic colposuspension for treatment of stress incontinence. Eur J Obstet Gynecol Reprod Biol. 1998; 79: 159-66.

17. Das S: Comparative outcome analysis of laparoscopic colposuspension, abdominal colposuspension and vaginal needle suspension for female urinary incontinence. J Urol. 1998; 160: 368-71.

18. Saidi MH, Shannon G, Ingrid PS, Saidi J, Sadler RK, Diaz KC: Extraperitoneal laparoscopic colposuspension: Short-term cure rate, complications, and duration of hospital stay in comparison with Burch Colposuspension. Obst Gynecol. 1998; 92: 619-21.

19. Moehrer B, Ellis G, Carey M, Wilson PD: Laparoscopic colposuspension for urinary incontinence in women (Cochrane Review). In: The Cochrane Library, Issue 3, 2003. Oxford: Update Software.

20. Jacome EG, Tutera G, Mattox FT: Laparoscopic Burch urethropexy in a private clinical practice. J Am Assoc Gynecol Laparosc. 1999; 6: 39-44.
Received: February 2, 2004

Accepted after revision: April 28, 2004

\section{Correspondence address:}

Dr. Carlos Alberto Bezerra

Rua Afonso Pena, 229 / 72

São Caetano do Sul, SP, 09541-400, Brazil

Fax: + 5511 4121-7372

E-mail:bezerrac@uol.com.br 